\title{
First observations of simultaneous interhemispheric conjugate high-latitude thermospheric winds
}

\author{
M. J. Kosch, ${ }^{1}$ C. Anderson, ${ }^{2}$ H.-C. I. Yiu, ${ }^{3}$ A. C. Kellerman, ${ }^{2}$ R. A. Makarevich, ${ }^{2}$ \\ A. Aruliah, ${ }^{3}$ M. Conde, ${ }^{4}$ E. Griffin, ${ }^{3}$ T. Davies, ${ }^{2}$ I. McWhirter, ${ }^{3}$ and P. L. Dyson ${ }^{2}$ \\ Received 7 December 2009; revised 7 May 2010; accepted 11 May 2010; published 28 September 2010.
}

[1] We report the first observations of simultaneous high-latitude interhemispheric $F$ region neutral wind fields by combining the $630 \mathrm{~nm}$ optical measurements from two scanning Doppler imagers (SDIs) and three Fabry-Perot interferometers (FPIs) for a period exceeding $5 \mathrm{~h}$. From the Southern Hemisphere, a SDI at Mawson and a FPI at Davis, both in Antarctica, are geomagnetically mapped onto the Northern Hemisphere. These data are combined in the Northern Hemisphere with a SDI at Longyearbyen, Svalbard, and two FPIs near Kiruna in Sweden and Sodankyla in Finland. Geomagnetic conditions were moderate $\left(K p=3^{-}-3^{+}\right)$and steady although the interplanetary magnetic field $B_{z}$ component did change polarity several times. There is good agreement between the conjugate $630 \mathrm{~nm}$ optical intensities and wind vectors where the two SDIs' fields of view overlap. All wind field vectors are overlaid onto the northern Super Dual Auroral Radar Network ion convection contours. Qualitatively, the agreement between neutral and ion flow is remarkably good throughout the study interval, even down to mesoscale spatial size.

Citation: Kosch, M. J., et al. (2010), First observations of simultaneous interhemispheric conjugate high-latitude thermospheric winds, J. Geophys. Res., 115, A09328, doi:10.1029/2009JA015178.

\section{Introduction}

[2] The Earth's upper atmosphere between 100 and $300 \mathrm{~km}$ altitude consists mostly of neutral oxygen atoms and nitrogen molecules, of which less than $1 \%$ is ionized. It is well established that high-latitude thermospheric neutral circulation in the $F$ layer is driven by ion drag, solar heating, advection, viscous, and Coriolis forces, whereby ion drag and solar heating are normally the dominant driving forces [e.g., Killeen and Roble, 1984]. Modeling studies show that at high latitudes, magnetospheric convection effectively controls the thermospheric wind circulation through ion-neutral collisions [e.g., Killeen and Roble, 1988]. The neutral winds at $F$ region altitudes generally follow but lag behind the ion drift pattern of magnetospheric convection [Killeen and Roble, 1984, 1988]. The large-scale pattern of high-latitude ionospheric circulation is primarily driven by the solar wind through magnetic reconnection of the frozen-in interplanetary magnetic field (IMF) with the Earth's geomagnetic field [e.g., Chisham et al., 2008]. Hence, the magnitude and direction of the IMF $B_{z}$ and $B_{y}$ components play a key role in ionospheric and thermospheric circulation at high latitudes [e.g., Chisham et al., 2007] whereby reconnection is much

\footnotetext{
${ }^{1}$ Department of Communication Systems, Lancaster University, Lancaster, UK.

${ }^{2}$ Department of Physics, La Trobe University, Melbourne, Australia.

${ }^{3}$ Department of Physics and Astronomy, University College London, London, UK.

${ }^{4}$ Geophysical Institute, University of Alaska, Fairbanks, Alaska, USA.

Copyright 2010 by the American Geophysical Union. 0148-0227/10/2009JA015178
}

more prevalent for $B_{z}$ negative. Satellite [Heelis, 1984; Haaland et al., 2007] and ground-based radar [Ruohoniemi and Greenwald, 1996, 2005] observations show that highlatitude ionospheric convection is normally ordered into large-scale dusk and dawn convection cell pairs in each hemisphere, with antisunward flow over the polar cap returning to the dayside via the dawn and dusk flanks. Increasingly, negative $B_{z}$ results in greater plasma flow. However, if $B_{z}$ is strongly positive then three or four convection cells with weak flow may form. The site of magnetic reconnection shifts duskward or dawnward for $B_{y}$ positive or negative, respectively, in the Northern Hemisphere [Ruohoniemi and Greenwald, 1996, 2005]. $B_{y}$ positive (negative) results in the dawn/dusk cell becoming more round/crescent (crescent/round) shaped in the Northern Hemisphere. The round cell is larger, especially for $B_{y}$ negative, while the crescent-shaped cell also shifts across the midnight magnetic local time meridian. These $B_{y}$ morphological effects are oppositely directed in the Southern Hemisphere but are essentially identical if the sign of $B_{y}$ is switched [Haaland et al., 2007]. However, hemispheric asymmetries do occur [Ruohoniemi and Greenwald, 2005] because of differences in ionospheric conductivity [Tanaka, 2001].

[3] Ionospheric circulation starts to respond to IMF changes at the dayside magnetopause in about $2 \min$ [Ruohoniemi and Greenwald, 1998], reaching a new steady state in about 20 min [Heelis et al., 2002], although there can be considerable variability on the time scale of minutes even for a reasonably constant IMF [Bristow et al., 2004]. Thermospheric neutral circulation, with its much greater inertia and 
Table 1. List of Optical Instrument Location Names, Geographic, and Geomagnetic Coordinates, Magnetic Local Time Relative to Universal Time, the Average Data Cadence, the SDI Effective Field of View or FPI Zenith Angle, and the Total Number of Line-of-Sight Measurements

\begin{tabular}{|c|c|c|c|c|c|c|c|c|}
\hline Location & $\begin{array}{l}\text { Geographic } \\
\text { Latitude }\end{array}$ & $\begin{array}{l}\text { Geographic } \\
\text { Longitude }\end{array}$ & $\begin{array}{l}\text { Geomagnetic } \\
\text { Latitude }\end{array}$ & $\begin{array}{l}\text { Geomagnetic } \\
\text { Longitude }\end{array}$ & $\begin{array}{l}\text { Magnetic } \\
\text { Local Time } \\
\text { (h) }\end{array}$ & $\begin{array}{l}\text { Cadence } \\
\text { (min) }\end{array}$ & $\begin{array}{l}\text { SDI Field of View } \\
\text { or FPI Zenith Angle }\end{array}$ & $\begin{array}{l}\text { No. of } \\
\text { Points }\end{array}$ \\
\hline Mawson SDI & $67.6^{\circ} \mathrm{S}$ & $62.9^{\circ} \mathrm{E}$ & $70.4^{\circ} \mathrm{S}$ & $90.5^{\circ} \mathrm{E}$ & $\mathrm{UT}+1.3$ & 3.9 & $144^{\circ}$ & 61 \\
\hline Davis FPI & $68.6^{\circ} \mathrm{S}$ & $78.0^{\circ} \mathrm{E}$ & $74.7^{\circ} \mathrm{S}$ & $100.5^{\circ} \mathrm{E}$ & $\mathrm{UT}+2.0$ & 20.5 & $30^{\circ}$ & 8 \\
\hline Longyearbyen SDI & $78.2^{\circ} \mathrm{N}$ & $16.0^{\circ} \mathrm{E}$ & $75.4^{\circ} \mathrm{N}$ & $111.7^{\circ} \mathrm{E}$ & $\mathrm{UT}+3.1$ & 8.0 & $134^{\circ}$ & 25 \\
\hline KEOPS FPI & $67.9^{\circ} \mathrm{N}$ & $21.0^{\circ} \mathrm{E}$ & $64.9^{\circ} \mathrm{N}$ & $103.0^{\circ} \mathrm{E}$ & $\mathrm{UT}+2.6$ & 3.0 & $45^{\circ}$ & 7 \\
\hline Sodankyla FPI & $67.4^{\circ} \mathrm{N}$ & $26.6^{\circ} \mathrm{E}$ & $64.1^{\circ} \mathrm{N}$ & $107.2^{\circ} \mathrm{E}$ & $\mathrm{UT}+2.9$ & 6.2 & $45^{\circ}$ & 7 \\
\hline
\end{tabular}

other forces acting, takes an additional 55 min on average to adjust to the new ion circulation [Heelis et al., 2002], although there is large variability $(0.5-3.5 \mathrm{~h})$ depending on geomagnetic activity [Killeen et al., 1984, 1988; Kosch et al., 2001] and season. However, for steady state IMF, i.e., constant for an hour or more, the dominant ion drag force will ensure that high-latitude neutral and ion circulation are similar [e.g., Conde et al., 2001], especially in the $F$ layer dusk ion convection cell. For the dawn ion convection cell, circulation opposes the Coriolis force, meaning a higher iondrag force is required to make the neutrals conform to the ion flow [Thayer and Killeen, 1993]. If geomagnetic activity is particularly low for extended periods (e.g., $K p \leq 2$ ), then solar heating may dominate thermospheric circulation [Aruliah et al., 1991; McCormac et al., 1987]. Satellite observations of ionospheric convection and thermospheric winds have clearly shown that both motions are normally closely linked [e.g., Killeen et al., 1984, 1985, 1988, 1991a, 1991b]. These both demonstrate a clear morphological dependence on the IMF orientation [e.g., McCormac et al., 1985; Rees et al., 1986; Thayer et al., 1987; Killeen and Roble, 1988; Killeen et al., 1991a].

[4] Because of the interhemispheric large-scale symmetry of the geomagnetic field, it is reasonable to expect that many phenomena should also be hemispherically conjugate. Evidence for high-latitude interhemispheric conjugate ion flow exists from ground-based radar observations [Hosokawa et al., 2003; Grocott et al., 2005; Lu et al., 1994], although a time difference of a few minutes between the hemispheres can occur [Chisham et al., 2000]. Likewise, evidence for high-latitude interhemispheric conjugacy for particle precipitation exists from combined satellite and ground-based optical [Burns et al., 1990], ground-based optical [StenbaekNielsen et al., 1972; Fujii et al., 1987; Sato et al., 2005], riometer [Nishino et al., 2000; Yamagishi et al., 2000], and radar [Yeoman et al., 1999] observations. However, a time difference of a few minutes between hemispheres can occur [Chisham et al., 2000; Yamagishi et al., 2000]. StenbaekNielsen and Otto [1997] found that diffuse auroras could be interhemispheric conjugate whereas discrete auroras were not necessarily conjugate [Laundal and Østgaard, 2009]. Interhemispheric neutral thermospheric flow does not seem to have been studied at all.

[5] This study uses scanning Doppler imagers (SDIs) and Fabry-Perot interferometers (FPIs) located in the Arctic and Antarctic and several Super Dual Auroral Radar Network (SuperDARN) radars. High-latitude thermospheric neutral winds have been derived from Doppler measurements of the $630 \mathrm{~nm}$ emission in the $F$ layer, using the SDIs and FPIs
[Hernandez, 1986], and high-latitude $F$ region ion convection from the Doppler shift of decameter-scale field-aligned plasma irregularities, as observed by the crossed beam HF radar SuperDARN network [Greenwald et al., 1995; Chisham et al., 2007]. Traditionally, the neutral wind vectors determined using FPIs have been derived by scanning the sky at different azimuths at a fixed zenith angle for an assumed altitude, typically $240 \mathrm{~km}$. This technique is greatly enhanced by the recent development of SDIs, which can derive lineof-sight wind measurements from many tens of softwaredefined directions simultaneously in a wide field of view [Conde and Smith, 1997, 1998]. The typical time resolution of this optical technique is 1-20 min, depending on the emission intensity. The SuperDARN system currently consists of 16 Northern Hemisphere and 6 Southern Hemisphere radars, mostly at high latitudes. Each radar is designed for a spatial and temporal resolution of $\sim 50 \mathrm{~km}$ and $2 \mathrm{~min}$, respectively, although the spatial resolution is limited by the available backscatter. The wide longitudinal distribution of radars permits routine modeling of the global ion convection. The map potential technique of combining line-of-sight observations [Chisham et al., 2007; Ruohoniemi and Baker, 1998] produces plasma velocity vectors where radar data are available as well as large-scale plasma convection equipotential contours. All the SDI and FPI fields of view are covered by different SuperDARN radars.

[6] Interhemispheric conjugate optical studies are limited by the solar illumination, which varies with the seasons. Between Mawson $\left(67.6^{\circ} \mathrm{S}, 62.9^{\circ} \mathrm{E}\right)$ and Longyearbyen $\left(78.2^{\circ} \mathrm{N}, 16.0^{\circ} \mathrm{E}\right)$, the locations of our two SDIs, simultaneous nighttime optical observations are possible during the equinoxes, i.e., 14 February to 26 March and 18 September to 28 October each year, for durations up to almost $6 \mathrm{~h}$. We present the first comparison between interhemispheric neutral thermospheric winds, which not only are consistent with being conjugate but also show remarkable qualitative agreement with the pattern of ion convection present, even down to mesoscales of a few $100 \mathrm{~km}$.

\section{Observations and Discussion}

[7] For this study, we employed two SDIs, at Mawson in Antarctica [Anderson et al., 2009] and Longyearbyen on Svalbard Island, Norway [Aruliah et al., 2010; Griffin et al., 2008], and three FPIs, at Davis in Antarctica, near Kiruna in Sweden (Kiruna Esrange Optical Platform System, KEOPS), and Sodankyla in Finland. Table 1 shows the geographic and geomagnetic coordinates of each instrument, magnetic local time relative to universal time (UT), average data cadence, 


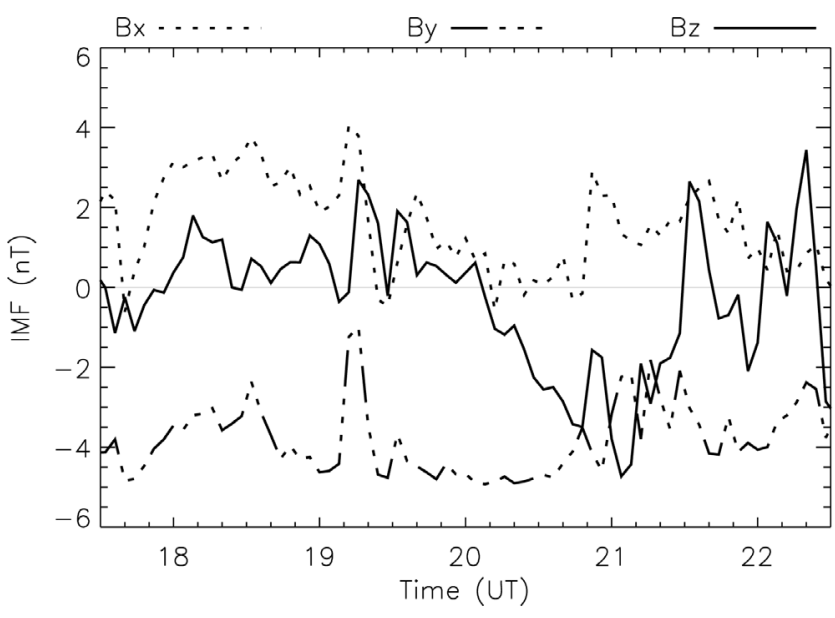

Figure 1. IMF components from the ACE satellite, delayed by $48 \mathrm{~min}$, including $B_{z}$ (solid), $B_{y}$ (dash-dotted), and $B_{x}$ (dot), from 1730 to 2230 UT on 3 October 2008.

SDI field of view or FPI zenith angle, and the number of line-of-sight measurements made in addition to viewing a calibration source. The SDIs measure all directions simultaneously, whereas the FPIs measure at selected azimuth and zenith angles sequentially. Mawson and Davis use variable integration times according to the emission intensity, so their data cadence is an average value. All instruments were observing the $630 \mathrm{~nm}$ emission at an assumed altitude of 240 $\mathrm{km}$. The SDIs have their observations integrated over contiguous azimuth and zenith angle zones using projected spatial centers of 106, 201, 304, 424, and $565 \mathrm{~km}$ for Mawson and 141, 307, and $481 \mathrm{~km}$ for Longyearbyen, measured radially from the local zenith. For the FPIs, Davis observed $139 \mathrm{~km}$ and KEOPS and Sodankyla $240 \mathrm{~km}$ from the local zenith with no spatial integration. The conjugate mapping was performed by the International Geomagnetic Reference Field/Definative Geomagnetic Reference Field (DGRF) model using corrected geomagnetic coordinates.

[8] We present interhemispheric conjugate ion convection and thermospheric winds in the $F$ region observed on 3 October 2008 from 1730 to 2240 UT, the maximum period of simultaneous darkness for Mawson and Longyearbyen on this day. Figure 1 shows the IMF components measured by the ACE satellite, delayed by $48 \mathrm{~min}$ to account for the average $\sim 645 \mathrm{~m} / \mathrm{s}$ solar wind speed and satellite position. $B_{x}$ and $B_{y}$ were essentially positive and continuously negative, respectively. $B_{z}$ was negative before $\sim 1800 \mathrm{UT}$, mostly positive between $\sim 1800$ and $\sim 2010$ UT, remained negative between $\sim 2010$ and $\sim 2130$ UT, after which it oscillated around zero. Geomagnetic activity was moderate, with $K p=$ $3^{+}, 3^{-}$and 3 during the study interval, and preceded by $21 \mathrm{~h}$ where $K p$ varied between $2^{+}$and $3^{+}$, i.e., fairly steady state. Therefore, ion drag is expected to be the dominant force determining thermospheric neutral circulation, and the neutral winds are expected to mimic the ion flow, especially in the dusk ion convection cell.

[9] Figure 2 shows the high-latitude ion convection potential maps. The top left frame shows the projected conjugate geographic fields of view of all the optical instruments assuming $240 \mathrm{~km}$ altitude. The color scheme is white for Mawson and blue for Davis, both geomagnetically mapped into the Northern Hemisphere, yellow for Longyearbyen, orange for KEOPS, and green for Sodankyla. The auroral Oval Variation, Assessment, Tracking, Intensity, and Online Nowcasting (OVATION) Web-based tool uses satellite-based Defense Meteorological Satellite Program (DMSP) particle data and Polar Ultraviolet imager (UVI) optical data to estimate the position of the high-latitude open-closed field line boundary [Carbary et al., 2003]. In the Northern Hemisphere, the Longyearbyen SDI was close to the open-closed field line boundary throughout the observation period so that the poleward and equatorward halves of its field of view were on open and closed field lines, respectively. The lower latitude KEOPS and Sodankyla FPIs were always on closed field lines. In the Southern Hemisphere, both the Mawson SDI and Davis FPI started on closed field lines at the beginning of the observation period. Mawson and Davis reached the openclosed field line boundary at $\sim 2030$ and $\sim 2130$ UT, respectively, such that their poleward fields of view were on open field lines at these times. Both stations' fields of view were essentially on open field lines at the end of their observations (2130 UT for Davis and 2240 UT for Mawson). The majority of the Southern Hemisphere data were taken on closed field lines, and we map all the data for the entire observation period to the Northern Hemisphere.

[10] Except for the top left frame, Figure 2 shows the highlatitude ion convection equipotential contours in half hour increments from 1730 to 2230 UT on 3 October 2008, using $3 \mathrm{kV}$ increments. For the Northern Hemisphere, the dusk and dawn cells are black and red, respectively. For the mapped Southern Hemisphere, the dusk and dawn cells are yellow and green, respectively. The arrows show the mean neutral wind direction for each optical instrument using the color scheme given earlier. In the Northern Hemisphere, the dusk/dawn cell was crescent/round shaped, and the opposite was true for the Southern Hemisphere. In the Northern Hemisphere, the crescent-shaped dusk cell (black) protruded over magnetic midnight into the dawn sector on the night side. This morphology is expected for $B_{y}$ negative. For both hemispheres, the round cells (red and yellow) were larger in size after 2000 UT when $B_{z}$ goes negative. Before 20 UT, when $B_{z}$ was of small amplitude and mostly positive, the ion flow was weaker compared to after 2000 UT. When $B_{z}$ was positive, there is evidence of multiple dawn (e.g., $18 \mathrm{UT}$, red) and dusk (e.g., 2130 UT onward, black) convection cells developing. This morphology is expected for the changing sign of $B_{z}$. Perhaps remarkably, the mapped Southern Hemisphere ion convection cells (green and yellow) spatially overlay those of the Northern Hemisphere (black and red) relatively well, at least qualitatively, before $2000 \mathrm{UT}$, when $B_{z}$ was mostly positive and of low amplitude. Hence, we can reasonably expect the neutral circulation to be interhemispheric conjugate. After 2000 UT when $B_{z}$ went negative, it is clear that any large-scale comparison breaks down and the global-scale morphology of the ion convection in opposite hemispheres is quite different. However, in the combined SDI and FPI fields of view the ion convection, perhaps by chance, retains a strong qualitative interhemispheric similarity, as is more easily seen in Figure 3 (discussed below). Hence, at least in the combined SDI and FPI fields of view, we can reasonably expect the neutral circulation to continue to follow the ion convection with a time lag and therefore remain interhemispheric conjugate. 

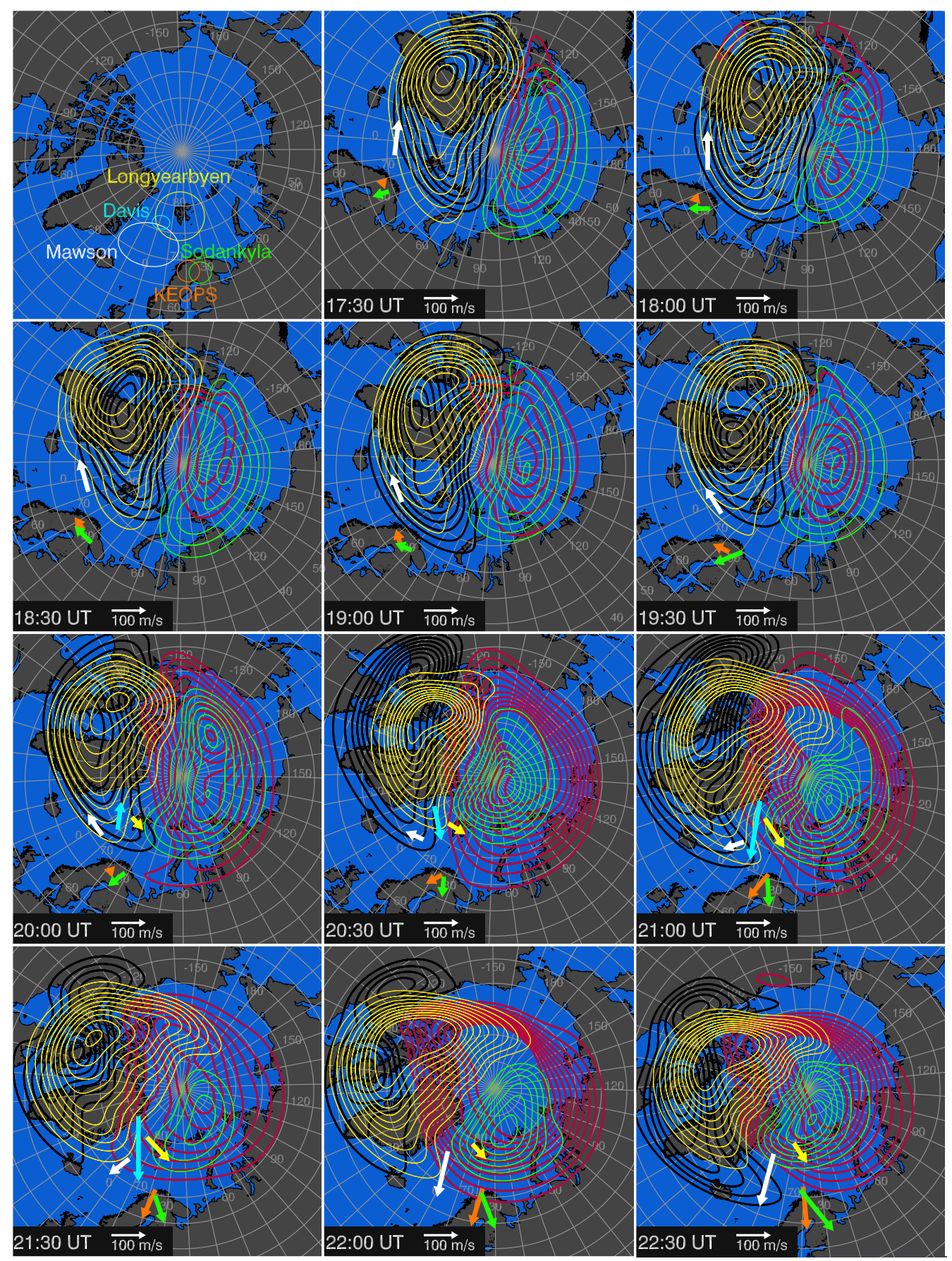

Figure 2. The top left frame shows the projected conjugate geographic fields of view of all the optical instruments assuming $240 \mathrm{~km}$ altitude. The color scheme is as follows: the Mawson SDI is white and Longyearbyen SDI is yellow, and the Davis FPI is blue, KEOPS FPI is orange, and Sodankyla FPI is green. For the other frames, the arrows show the mean neutral wind for each of the instruments. The high-latitude ion convection equipotential contours are shown in half hour increments from 1730 to 2230 UT on 3 October 2008, using $3 \mathrm{kV}$ increments. For the Northern Hemisphere, the dusk and dawn cells are black and red, respectively. For the mapped Southern Hemisphere, the dusk and dawn cells are yellow and green, respectively. Magnetic midnight is toward the bottom of each frame.

[11] Figure 3, top left frame, shows the northern geographic locations of the projected wind measurements for all optical instruments. The color coding is the same as Figure 2. The Longyearbyen and Davis wind data started at 2000 UT because of twilight and local moonlight illuminated cloud, respectively. The Davis data ended at $\sim 2130$ UT because of twilight. The remaining panels of Figure 3 show the $630 \mathrm{~nm}$ thermospheric wind vectors in half hour increments from 1730 to 2230 UT on 3 October 2008. All wind vectors are centered on their projected geographic location. The larger 


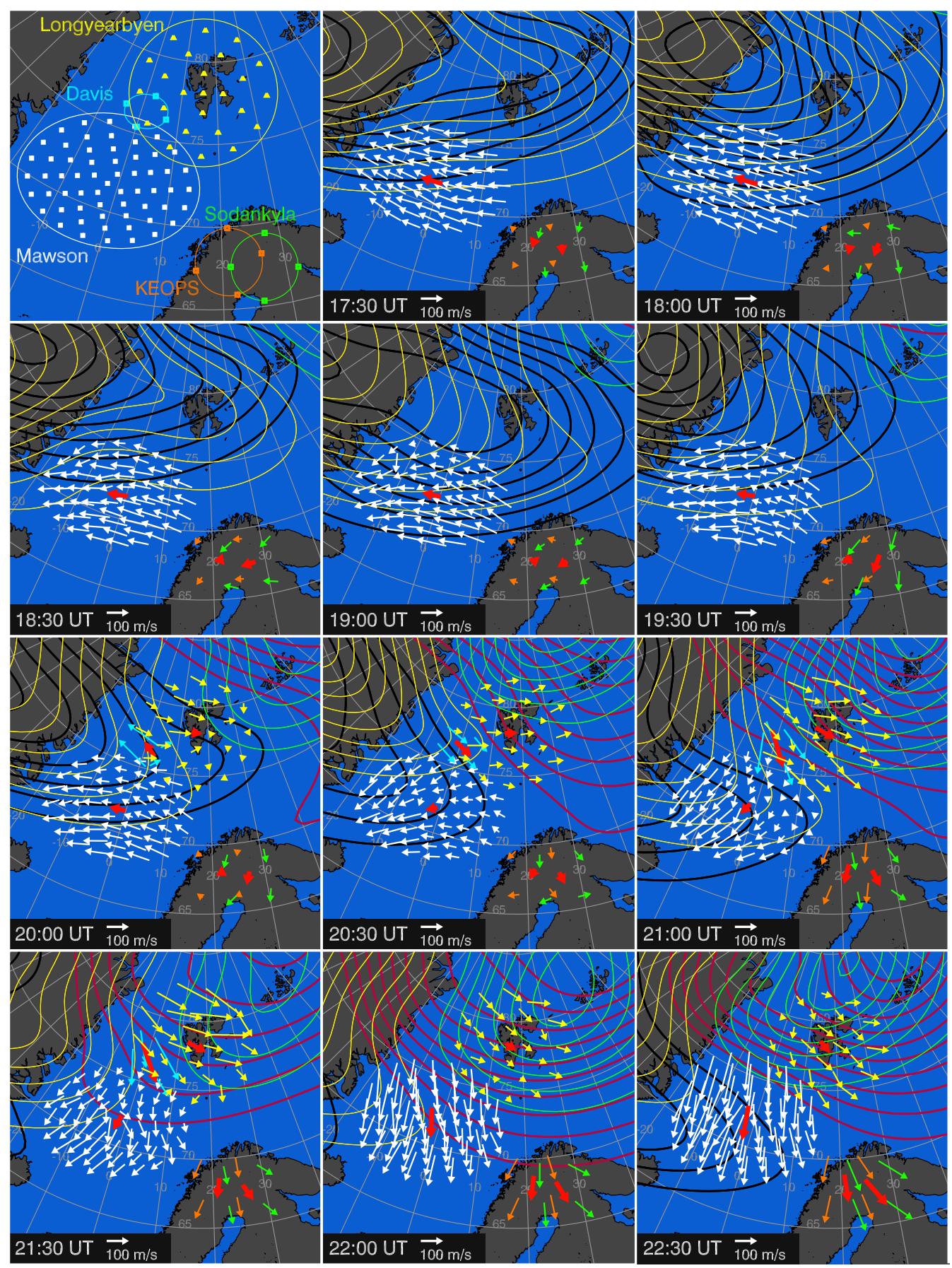

Figure 3. The top left frame shows the projected conjugate geographic locations in the Northern Hemisphere where thermospheric wind measurements took place for all optical instruments assuming $240 \mathrm{~km}$ altitude. For the other frames, the $630 \mathrm{~nm}$ thermospheric wind vectors are shown in half hour increments from 1730 to 2230 UT on 3 October 2008. The wind vectors are for the Mawson SDI (white) and Davis FPI (blue), geomagnetically mapped into the Northern Hemisphere, and the Longyearbyen SDI (yellow), the KEOPS FPI (orange), and Sodankyla FPI (green). The larger red vectors represent the mean wind flow for each instrument. For the Northern Hemisphere, the SuperDARN ion convection equipotential contours, using $3 \mathrm{kV}$ increments, are overlaid with black and red for the dusk and dawn convection cells, respectively. For the mapped Southern Hemisphere, the dusk and dawn cells are yellow and green, respectively.

red vectors represent the mean wind flow for each instrument. Each FPI wind vector was produced from two orthogonal line-of-sight components, assuming the vertical wind was small. For the SDIs, the information from all line-of-sight
Doppler measurements was used to derive an equivalent horizontal wind field assuming the vertical winds were small [Anderson et al., 2009, and references therein]. The optical measurements were not synchronized, but none are more than 
4 min away from the time given, except for Davis with up to $10 \mathrm{~min}$ discrepancy. SuperDARN ion convection equipotential contours, using $3 \mathrm{kV}$ increments, were overlaid with black and red for the northern and yellow and green for the southern dusk and dawn convection cells, respectively. In the Northern Hemisphere, there were relatively few direct SuperDARN measurements over the European sector, with limited data overhead of Svalbard, where the Longyearbyen SDI is located, some data almost continuously south of Svalbard, which is in the Mawson conjugate field of view, and east of Iceland, which is south-west of the Mawson conjugate field of view. Continuous data from the sunlit Canadian sector provided good coverage for the ion convection model. In the Southern Hemisphere, there was essentially no SuperDARN radar backscatter within the Mawson and Davis fields of view. Hence, the ion convection equipotentials rely on the map potential modeling technique using whatever data are available from the other radars. The ion velocity vectors are not shown.

[12] Figure 3 is now briefly discussed with reference to the northern ion convection pattern. At $1730 \mathrm{UT}, B_{z}$ was turning negative and the Mawson vectors were westward and nearparallel to the ion convection contours. At $1800 \mathrm{UT}, B_{z}$ started to turn positive and the Mawson vectors continued as before in agreement with the northern part of the KEOPS and Sodankyla fields of view. By 1900 UT, the Mawson vectors continued westward parallel to the ion convection contours. KEOPS and Sodankyla showed mostly westward flow in good agreement with the ion convection. This wind pattern basically persisted until 1930 UT; however, KEOPS and Sodankyla showed a stronger southward flow component consistent with the ion flow reversal of the approaching dawn convection cell. At $2000 \mathrm{UT}, B_{z}$ started to turn negative and Longyearbyen showed eastward flow, whereas Mawson continued to show westward flow, consistent with the dusk cell ion convection. The Davis data show eastward and westward flow in its eastern and western conjugate field of view, respectively. At 2030 UT, the pattern from 2000 UT persisted, but Davis showed strong eastward flow everywhere consistent with Longyearbyen. At 2100 UT, Mawson showed a south-westward flow in its western and small nondirectional flow in its eastern conjugate fields of view. The former was consistent with the dusk ion convection cell, and the latter was consistent with the flow reversal region between the dusk and dawn convection cells. Longyearbyen showed a south-eastward flow consistent with the dawn ion convection cell. Davis showed a south and south-eastward flow consistent with both Mawson and Longyearbyen. KEOPS and Sodankyla both showed a southward flow consistent with the transition region between ion convection cells. KEOPS and Sodankyla had a small westward and eastward wind component consistent with the dusk and dawn cells, respectively. At this time, the agreement between all instruments was remarkably good despite the complex ion flow morphology associated with the transition between dusk and dawn convection cells. At $2130 \mathrm{UT}, B_{z}$ turned positive and the wind pattern from 2100 UT persisted except that Mawson was mostly in the ion convection transition region and Longyearbyen and Davis were partly in the dawn convection cell. Davis flow remained consistent with Mawson and Longyearbyen. At $2200 \mathrm{UT}$, IMF $B_{z}$ was negative and Longyearbyen was entirely within the dawn ion convection cell with south-eastward flow. Mawson remained partly in the transition region between the dusk and dawn ion convection cells with southward conjugate flow, consistent with KEOPS and Sodankyla. At $2230 \mathrm{UT}$, IMF $B_{z}$ was negative and Longyearbyen showed south-eastward flow consistent with the dawn ion convection cell. Mawson showed southward conjugate flow consistent with the dusk convection cell. KEOPS and Sodankyla showed south-eastward flow consistent with their position between the dusk and dawn ion convection cells. It is noteworthy that the Davis wind vectors often have a much larger magnitude than Mawson or Longyearbyen. Closer inspection of the Davis FPI data reveals that the assumption of small vertical winds was often not true during the study interval. Davis experienced vertical winds of up to $\pm 40 \mathrm{~m} / \mathrm{s}$. The problem is exacerbated by the relatively small zenith angle $\left(30^{\circ}\right)$ used at Davis. Hence, the horizontal wind magnitude has large uncertainty, but the vector direction is considered reliable.

[13] We have calculated the linear cross-correlation coefficient between the average Longyearbyen, and conjugate Mawson, wind vectors against the average ion flow vectors within each instrument's field of view in the Northern Hemisphere. Since SuperDARN data coverage was limited, the location of the ion flow data was variable. This calculation was not possible in the southern hemisphere for lack of SuperDARN data. Ion flow vector data was available for 2000-2130 UT for Longyearbyen, i.e., $1.5 \mathrm{~h}$ giving 38 data points, and 1700-2200 UT for Mawson, i.e., $5 \mathrm{~h}$ giving 116 data points. For Longyearbyen, the coefficient for vector direction is 0.38 with a lag of $34 \mathrm{~min}$ and the coefficient for vector magnitude is 0.39 with a lag of $32 \mathrm{~min}$. This indicates modest coupling between the $F$ layer ions and neutrals, as expected for ion drag-driven thermospheric winds. For Mawson, the coefficient for vector direction is 0.65 with a lag of $45 \mathrm{~min}$ and the coefficient for vector magnitude is 0.39 for a lag of 39 min. Bearing in mind that this correlation is for northern ion flow and southern neutral winds for Mawson and the modest number of data points for Longyearbyen, the coefficients are in good agreement with each other. This provides quantitative evidence that the thermospheric winds were indeed interhemispheric conjugate during our study interval, at least within the combined SDI and FPI fields of view.

[14] Overall, in a qualitative sense, the agreement between ion and neutral motion in Figure 3 is remarkably good taking into account the smoothing effect of the neutral winds and natural variability of the ion flow. Even details concerning the transition between the dusk and dawn ion convection cells are well reproduced in the neutral wind field. Bearing in mind that each degree in latitude is equivalent to $115 \mathrm{~km}$ in the thermosphere, the agreement between ion and neutral flow is remarkable right down to mesospatial scales. This remains true despite the fact that the global-scale Southern Hemisphere ion convection morphology started to deviate from that of the Northern Hemisphere after 2000 UT when $B_{z}$ went negative and that Davis and Mawson were increasingly on open magnetic field lines after $\sim 2030$ and $\sim 2130$ UT, respectively. This we attribute to the ion drag force [Killeen and Roble, 1984; Conde et al., 2001] from ion convection, which was interhemispheric conjugate, at least qualitatively, within the combined SDI and FPI fields of view during our study interval. 


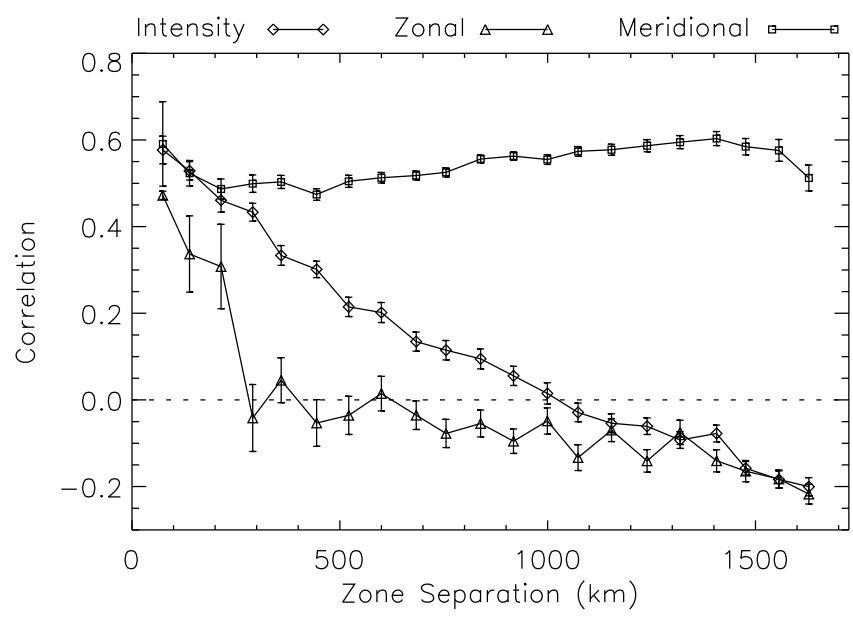

Figure 4. Correlation coefficient between all Mawson and Longyearbyen SDI sectors of uncalibrated $630 \mathrm{~nm}$ optical intensity (diamonds), zonal wind (triangles), and meridional wind (squares) vector components as a function of sector separation.

[15] Figure 4 shows the median correlation coefficient between all Mawson and Longyearbyen SDI zone pairs of uncalibrated $630 \mathrm{~nm}$ optical intensity (diamonds), zonal wind (triangles), and meridional wind (squares) vector components as a function of zone separation for 2000 to 2230 UT. For each of 1440 zone pairs between the SDIs (excluding zenith zones, where horizontal wind components were not derived), the great circle distance between the conjugate Mawson and Longyearbyen zones was calculated, along with the correlation in the 3 parameters. The correlation values were binned by zone separation using an $80 \mathrm{~km}$ bin width, the median of which is shown in each curve. Error bars show the standard error within each bin. The correlation of the wind components peaks for zero time lag and minimum zone separation. The meridional wind correlation peaks at 0.6 and is fairly constant with zone separation, consistent with the wind field mostly having an equatorward component throughout the study interval, as is evident from Figure 3. The zonal wind correlation peaks at 0.47 and rapidly decreases to near zero with zone separation, consistent with the predominant zonal wind field being westward for Mawson and eastward for Longyearbyen, as shown in Figure 3. This result may indicate that the spatial scale size of the winds in this region is $\sim 1000$ and $\sim 300 \mathrm{~km}$ meridionally and zonally, respectively. The intensity correlation peaks at 0.58 , monotonically decreasing with increasing zone separation, clearly indicating some conjugate relationship. However, Mawson intensity lagged Longyearbyen by about $4-8 \mathrm{~min}$ in the conjugate region, consistent with previous similar observations.

\section{Conclusion}

[16] Simultaneous observations of interhemispheric highlatitude $F$ region neutral winds are reported for the first time. Thermospheric wind data from two southern and three northern hemisphere optical instruments have been geomagnetically mapped onto the Northern Hemisphere ion convection contours for a $5 \mathrm{~h}$ period during moderate and steady state geomagnetic activity. There was remarkable agreement between the interhemispheric wind fields, and the Northern Hemisphere ion convection pattern, even down to mesoscale spatial size. These data demonstrate that for moderate and steady state geomagnetic activity, thermospheric wind circulation can be interhemispheric conjugate over several hours, following the ion convection despite changes in IMF $B_{z}$ polarity. This result also implies that for moderate and steady state geomagnetic activity, the neutral wind velocity may be taken as a proxy for ion velocity where plasma drift data is unavailable, at least in the dusk sector. However, further examples would need to be studied to confirm this.

[17] Acknowledgments. Operation of the SuperDARN radars in the northern hemisphere is supported by the national funding agencies of Canada, France, Japan, the United Kingdom, and the United States. C. Down is thanked for his assistance in producing the SuperDARN convection plots. The SPDF/Modelweb, available at http://modelweb.gsfc.nasa.gov/models/ $\mathrm{cgm} / \mathrm{cgm} . \mathrm{html}$, was used to generate the conjugate mapping, geomagnetic coordinates, and magnetic local times. The OVATION tool, available at http://sd-www.jhuapl.edu/Aurora/ovation/guidelines.html and developed by Johns Hopkins University/Applied Physics Laboratory, was used to determine open-closed field line boundary. IMF data are supported by the NASA/ ACE program. This research was also supported by the Australian Research Council's Discovery Project DP0557369 and by the Australian Antarctic Science Program. M.J.K. was the recipient of a La Trobe University Institute of Advanced Study Distinguished Visiting Fellowship. The Longyearbyen SDI was funded by the STFC grant PP/C50165X/1.

[18] Robert Lysak thanks the reviewers for their assistance in evaluating this paper.

\section{References}

Anderson, C., et al. (2009), Thermospheric winds and temperatures above Mawson, Antarctica, observed with an all-sky imaging Fabry-Perot spectrometer, Ann. Geophys., 27, 2225-2235.

Aruliah, A. L., et al. (1991), The combined effect of solar and geomagnetic activity on high-latitude thermospheric winds. Part I. Observations, J. Atmos. Terr. Phys., 53, 467-483.

Aruliah, A. L., et al. (2010), SCANDI-An all-sky Doppler imager for studies of thermospheric spatial structure, Ann. Geophys., 28, 549-567.

Bristow, W. A., et al. (2004), On the observed variability of the cross-polar cap potential, J. Geophys. Res., 109, A02203, doi:10.1029/2003JA010206.

Burns, G. B., et al. (1990), Optical auroral conjugacy: Viking UV imagersouth pole station ground data, J. Geophys. Res., 95, 5781-5790.

Carbary, J. F., et al. (2003), Auroral boundary correlations between UVI and DMSP, J. Geophys. Res., 108(A1), 1018, doi:10.1029/ 2002JA009378

Chisham, G., et al. (2000), High-time resolution conjugate SuperDARN radar observations of the dayside convection response to changes in IMF $B_{y}$, Ann. Geophys., 18, 191-201.

Chisham, G., et al. (2007), A decade of the Super Dual Auroral Radar Network (SuperDARN): Scientific achievements, new techniques, and future directions, Surv. Geophys., 28, 33-109, doi:10.1007/s10712-007-9017-8. Chisham, G., et al. (2008), Remote sensing of the spatial and temporal structure of magnetopause and magnetotail reconnection from the ionosphere, Rev. Geophys., 46, RG1004, doi:10.1029/2007RG000223.

Conde, M., and R. W. Smith (1997), Phase compensation of a separation scanned, all-sky imaging Fabry-Perot spectrometer for auroral studies, Appl. Optics, 36, 5441-5450.

Conde, M., and R. W. Smith (1998), Spatial structure in the thermospheric horizontal wind above Poker Flat, Alaska, during solar minimum, J. Geophys. Res., 103, 9449-9471.

Conde, M., et al. (2001), Assimilated observations of thermospheric winds, the aurora, and ionospheric currents over Alaska, J. Geophys. Res., 106, $10,493-10,508$.

Fujii, R., et al. (1987), Conjugacies of pulsating auroras by all-sky TV observations, Geophys. Res. Lett., 14, 115-118.

Greenwald, R. A., et al. (1995), DARN/SuperDARN: A global view of the dynamics of high-latitude convection, Space Sci. Rev., 71, 761-796.

Griffin, E. M., et al. (2008), Upper thermospheric neutral wind and temperature measurements from an extended spatial field, Ann. Geophys., 26 , 2649-2655. 
Grocott, A., et al. (2005), Interhemispheric observations of the ionospheric signature of tail reconnection during IMF-northward non-substorm intervals, Ann. Geophys., 23, 1763-1770.

Haaland, S. E., et al. (2007), High-latitude plasma convection from Cluster EDI measurements: Method and IMF dependence, Ann. Geophys., 25, 239-253.

Heelis, R. A. (1984), The effects of interplanetary magnetic field orientation on dayside high-latitude ionospheric convection, J. Geophys. Res. 89, (A5) 2873-2880.

Heelis, R. A., et al. (2002), Ion and neutral motions observed in the winter polar upper atmosphere, J. Geophys. Res., 107(A12), 1476, doi:10.1029/ 2002JA009359.

Hernandez, G. (1986), The Fabry-Perot Interferometer, Cambridge Univ. Press, New York.

Hosokawa, K., et al. (2003), Interhemispheric comparison of spectral width boundary as observed by SuperDARN radars, Ann. Geophys., $21,1553-1565$.

Killeen, T. L., and R. G. Roble (1984), An analysis of the high-latitude thermospheric wind pattern calculated by a thermospheric general circulation model 1. Momentum forcing, J. Geophys. Res., 89, 7509-7522.

Killeen, T. L., and R. G. Roble (1988), Thermospheric dynamics: Contributions from the first 5 years of the Dynamics Explorer program, Rev Geophys., 26, 329-367.

Killeen, T. L., et al. (1984), Ion-neutral coupling in the high-latitude $F$ region: Evaluation of ion heating terms from Dynamics Explorer 2 , J. Geophys. Res., 89, 7495-7508.

Killeen, T. L., et al. (1985), Neutral motions in the polar thermosphere for northward interplanetary magnetic field, Geophys. Res. Lett., 12, $159-162$.

Killeen, T. L., et al. (1988), On the relationship between dynamics of the polar thermosphere and morphology of the aurora: Global-scale observations from Dynamics explorers 1 and 2, J. Geophys. Res., 93, 2675-2692.

Killeen, T. L., et al. (1991a), On the dynamics and composition of the high-latitude thermosphere, J. Atmos. Terr. Phys., 53, 797-815.

Killeen, T. L., et al. (1991b), Thermospheric dynamics, energetics, and composition at auroral latitudes, Auroral Physics, 67-81, Cambridge Univ. Press.

Kosch, M. J., et al. (2001), High-latitude ground-based observations of the thermospheric ion drag time constant, Geophys. Res. Lett., 28 , 1395-1398.

Laundal, K. M., and N. Østgaard (2009), Asymmetric auroral intensities in the Earth's Northern and Southern hemispheres, Nature, 460, 491-493, doi: 10.1038 /nature 08154

Lu, G., et al. (1994), Interhemispheric asymmetry of the high-latitude ionospheric convection pattern, J. Geophys. Res., 99, 6491-6510.

McCormac, F. G., et al. (1985), Configuration of the high-latitude thermospheric neutral circulation for IMF $\mathrm{B}_{\mathrm{y}}$ negative and positive, Geophys. Res. Lett., 12, 155-158.

McCormac, F. G., et al. (1987), Circulation of the polar thermosphere during geomagnetically quiet and active times as observed by Dynamics Explorer 2, J. Geophys. Res., 92, 10,133-10,139.

Nishino, M., et al. (2000), Conjugate features of daytime absorption associated with specific changes in the solar wind observed by inter- hemispheric high-latitude imaging riometers, Adv. Polar Upper Atmos. Res., 14, 76-92.

Rees, D., et al. (1986), A theoretical and empirical study of the response of the high-latitude thermosphere to the sense of the "Y" component of the interplanetary magnetic field, Planet. Space Sci., 34, 1-40.

Ruohoniemi, J. M., and K. B. Baker (1998), Large-scale imaging of highlatitude convection with Super Dual Auroral Radar Network HF radar observations, J. Geophys. Res., 103, 20,797-20,811.

Ruohoniemi, J. M., and R. A. Greenwald (1996), Statistical patterns of high-latitude convection obtained from Goose Bay HF radar observations, J. Geophys. Res., 101, 21,743-21,763.

Ruohoniemi, J. M., and R. A. Greenwald (1998), The response of highlatitude convection to a sudden southward IMF turning, Geophys. Res. Lett., 25, 2913-2916.

Ruohoniemi, J. M., and R. A. Greenwald (2005), Dependencies of highlatitude plasma convection: Consideration of interplanetary magnetic field, season, and universal time factors in statistical patterns, J. Geophys. Res., 110, A09204, doi:10.1029/2004JA010815.

Sato, N., et al. (2005), Tracing geomagnetic conjugate points using exceptionally similar synchronous auroras, Geophys. Res. Lett., 32, L17109, doi:10.1029/2005GL023710.

Stenbaek-Nielsen, H. C., et al. (1972), Relative motion of auroral conjugate points during substorms, J. Geophys. Res., 77, 1844-1858.

Stenbaek-Nielsen, H. C., and A. Otto (1997), Conjugate auroras and the interplanetary magnetic field, J. Geophys. Res., 102, 2223-2232.

Tanaka, T. (2001), Interplanetary magnetic field $\mathrm{B}_{\mathrm{y}}$ and auroral conductance effects on high latitude ionospheric convection patterns, J. Geophys. Res., 106, 24,505-24,516.

Thayer, J. P., and T. L. Killeen (1993), A kinematic analysis of the highlatitude thermospheric neutral circulation pattern, J. Geophys. Res., 98 , $11,549-11,565$

Thayer, J. P., et al. (1987), Thermospheric neutral wind signature dependent on the east-west component of the interplanetary magnetic field for northern and southern hemisphere as measured from Dynamics Explorer-2, Ann. Geophys., 5A, 363-368.

Yamagishi, H., et al. (2000), Interhemispheric conjugacy or auroral poleward expansion observed by conjugate imaging riometers at $\sim 67^{\circ}$ and $75^{\circ}-77^{\circ}$ invariant latitude, Adv. Polar Upper Atmos. Res., 14, 12-33.

Yeoman, T. K., et al. (1999), An interhemispheric study of the ground magnetic and ionospheric electric fields during the substorm growth phase and expansion phase onset, J. Geophys. Res., 104, 14,867-14,877.

C. Anderson, T. Davies, P. L. Dyson, A. C. Kellerman, and R. A Makarevich, Department of Physics, La Trobe University, Melbourne, Victoria 3086, Australia.

A. Aruliah, E. Griffin, I. McWhirter, and H.-C. I. Yiu, Department of Physics and Astronomy, University College London, Gower St., London WC1E 6BT, UK.

M. Conde, Geophysical Institute, University of Alaska, 903 Koyukuk Dr., Fairbanks, AK 99775, USA.

M. J. Kosch, Department of Communication Systems, Lancaster University, Infolab 21, Lancaster, Lancashire LA1 4WA, UK. (m.kosch@ lancaster.ac.uk 